\title{
Urban neighbourhood characteristics influence on a building indoor environment
}

\author{
Parham A. Mirzaei ${ }^{1}$, Dave Olsthoorn ${ }^{2}$, Michael Torjan ${ }^{2}$ and Fariborz Haghighat ${ }^{2 *}$ \\ ${ }^{1}$ Architecture and Built Environment Department, The University of Nottingham \\ University Park, Nottingham, NG7 2RD, UK \\ ${ }^{2}$ Department of Building, Civil and Environmental Engineering, \\ Concordia University, Montreal, Canada, H3G 1M8
}

\begin{abstract}
The urban heat island (UHI) is exacerbated during heat waves, which have been reported to be more frequent in recent years. Unwanted consequences of the UHI not only include an increase in mean/peak energy demand, but an escalation in the heat-related mortality and disease. Although UHI mitigation strategies are being implemented by cities, they serve as mid to longterm solutions. The implementation of short-term mitigation strategies is paramount for cities to reduce the immediate risks of the heat-related hazards. Various prognostic tools have been developed to empower urban planners and decision makers in minimizing the related risks. These tools are mainly based on stationary parameters, such as the average surface temperature of a city, and are independent of land-use/land-cover (LULC). Furthermore, the outdoor temperatures are utilized to develop such models. However, heat-related risks occur mostly in indoor spaces, and correlations between indoor and outdoor spaces are rarely considered.

In this study, a predictive model for the indoor air temperature of buildings is developed using the artificial neural network (ANN) concept. A four-month measurement campaign was conducted to obtain indoor temperatures of more than 50 buildings located on the island of Montreal. The area is then separated into 11 regions, each containing at least one of the measured buildings. The ANN model is then trained to be sensitive to the neighborhood's characteristics and LULC of each region. The surrounding radial area that influences the building's indoor temperature is first defined within an effective radius, by analyzing areas with radii ranging from $20 \mathrm{~m}$ to $500 \mathrm{~m}$ in $20 \mathrm{~m}$ increments. Hence, the effective radius is found for each region to be within a radial area, where the environment beyond its limit does not significantly impact the building indoor air temperature. This technique trains a single model for the city, encompassing the unique characteristics of the sub-regions that contain buildings under study. An effective radius was established to lie within $320 \mathrm{~m}$ to $380 \mathrm{~m}$. Analysing surrounding radial areas within this range enabled the network to effectively forecast future indoor conditions resulting from UHI effects, producing hourly indoor temperature predictions with an MSE of 0.68. Furthermore, the ability of the developed tool in the city planning is investigated with an additional case study.
\end{abstract}

Keywords: Urban heat Island, Indoor Environment, Green, Artificial Neural Network, Health, Landuse/Land-cover, Mitigate, Urban Planning

Corresponding Author: Fariborz Haghighat (Fariborz.Haghighat@Concordia.ca) 


\section{Introduction}

Heat waves have become longer, more intense and more frequent (Meehl and Tebaldi, 2004). Such temperature increases are exacerbated by urban heat island (UHI) effect, where the metropolitan is significantly warmer than its surrounding rural area. UHI effects occurs within cities as the energy balance of the landscape becomes artificially unbalanced with the blockage effect of constructed buildings and infrastructure, the generation of more anthropogenic heat, and the absorption of more solar irradiance. The resulting consequence of such effects is an inhomogeneous tempo-spatial temperature elevation within urban environments. Furthermore, the UHI causes an increase in the mean/peak energy demand (Mirzaei and Haghighat, 2010; Santamouris, 2014). It is also well documented that there is an increase in mortality and morbidity associated with the UHI as the temperature in cities increases (Doyon et al. 2008, Gabriel and Endlicher, 2011).

To mitigate the UHI, several mid/long-term diagnostic plans (e.g. vegetation and greenery) have been proposed and adapted by cities. From an urban-planner or a decision maker's point of view, however, providing a prognostic short-term plan (e.g. enhancing the urban ventilation with better design of future planned buildings) for the vulnerable sectors of a city and reinforcing the poorly designed areas against the heat-related risks of the UHI with mid/long-term plans is of paramount importance. Among many efforts, cities attempt to bring awareness to the local inhabitants and to encourage their assistance with anticipatory heat alert systems in the case of heat waves. The relation between the ambient temperature and heat-related morbidity/mortality rates is commonly utilized to develop predictive models, enabling the public to understand the level of the heat-related risk. Thus, the developed anticipatory models should help forecast the associated heat risk with high spatial resolution in the order of a few hundred meters. For example, Mirzaei et al. (2012) developed an alert system for the island of Montreal to recognize the vulnerable regions during UHI.

The predictive models are mainly based on correlations, which are developed to show how the rate of mortality is dependent on the temperature increase. This includes simple linear regressions and more advanced methods such as time-series analysis. In these models, the parameters such as the threshold temperature, the number of hot days, daily mean, maximum and minimum temperature, peak temperature, extremes/weekly/10-day average temperatures, and age of occupants are the key parameters in heat-related mortalities. More advanced correlations include the social and environmental aspects such as vegetation, age of occupants, genetics, socioeconomic status, health behaviors, and physiologic differences. The form of these correlations is mainly $\mathbf{J}$ and U-shaped, defining the mortality rate against the temperature extremes (Basu and Samet, 2002). For example, Chen et al. (2014) identified mortality rate to be a function of urban vegetation ratio, the mean daily indoor temperatures exceeding $28.5^{\circ} \mathrm{C}$, and the building orientation. Moreover, Doyon et al. (2008) anticipated that the annual mortality rate increases from about $0.5 \%$ in 2020 and reaches $3 \%$ around the year 2080 .

In the mentioned studies, however, the correlations are extracted between the mortality rate and an overall characteristic of the city such as the ambient air, meaning that the spatial distribution and intensity variation of the UHI throughout a city is mostly neglected and assumed to be constant. On the other hand, the impacts of the heterogeneity of land use/land cover (LULC) in the formation of UHI is well investigated, meaning that the heterogeneous nature of urban morphology and population density causes a different UHI intensity throughout a city. As a result, UHI analysis needs to be fractioned to a smaller scale, facilitating a more in-depth investigation of the parameters that influence the exacerbation of the UHI. For example, Ivajnsic et al. (2014) 
developed a regression based on five parameters; distance to an urban area, topographic position index, land-cover diversity, building volume per area, and northern orientation. The regressive model was developed for Ljutomer city (Slovenia) to explain spatial variation in the mean air temperature. Another study of UHI within Chicago by Coseo and Larsen (2014) explains that during extreme heat events, 91\% of air temperature variation is related to the urban block's percentages of impervious surface and tree canopy. Su et al. (2012) utilized geographically weighted regression to find the relationships between LULC (i.e. built-up, water, paddy field, and other vegetation) and the surface temperature of TaoYuan city-Taiwan. In another investigation, Zheng et al. (2014) examined the effect of the composition and the spatial pattern of anthropogenic LULC temperature of Phoenix-Arizona. Furthermore, Chun and Guldmann (2014) reported the impacts of solar radiation, open spaces, vegetation, building rooftop areas, and water on the Columbus city's surface temperatures.

Thus, as these studies demonstrate, the heterogeneous relationships between the LULC and urban temperatures should be included in the development of alert systems as the intensity of UHI varies according to the geographical and climatic characteristics of a city. For example, in a neighborhood with high albedo surface materials, the solar radiation is more likely to be absorbed and stored. In highly populated areas, mainly with narrow street canyons and high-rise buildings, the released anthropogenic heat is less ventilated by wind. The socioeconomic level is also known to be an influential factor in the release of heat within buildings, mainly as a result of air conditioning systems being frequently installed when the standard of living is above a certain threshold. In conclusion, the different types of LULCs throughout a city are the key elements in the alteration of UHI, as the portion of each above-mentioned parameter varies with them. The local nature of LULC therefore renders the UHI in a city heterogeneous in its temperature distribution. This evidently requires related countermeasures to be uniquely implemented within a city neighborhood. This simply implies that, for example, tree planting can be less effective in a regions where the main source of UHI is low-albedo materials, while refurbishing the surface coating with high-albedo materials can be more effective in reducing the UHI in that particular region.

As discussed earlier, regression models are a common approach to understanding the relationship between the LULC and the temperature. The complexity of the contributing parameters in the formation of the UHI normally causes a considerable discrepancy in these models, so more advanced models seem to be more effective than the latter models. In a comparative study, Ashtiani et al., (2014) proved that the artificial neural network (ANN) is more accurate approach for the prediction of indoor air temperature.

The objective of this study is to understand the impact that neighborhood characteristics and surrounding LULC have on the indoor temperature of a building. For this purpose, the building surrounding environment is analyzed as a radial area, with LULC categorized into five different types, including vegetation (grass and trees), buildings, water, and pavements (asphalt and cement). An ANN model is developed to investigate the correlation between indoor building temperature and the surrounding environment by analyzing areas with radii ranging from $20 \mathrm{~m}$ to $500 \mathrm{~m}$ with increments of $20 \mathrm{~m}$. Hence, the effective radius is found for each region to be within a radial area, where the environment beyond its limit does not significantly impact the building indoor air temperature. Parameters defining the influence of the surrounding environment include solar heat gain, local wind velocity, building orientation, outdoor conditions, vegetation, and thermal mass. The utilized data is obtained from a four-month measurement campaign in which 
indoor air temperature and relative humidity $(\mathrm{RH})$ of more than 50 buildings located on the island of Montreal were measured for the summertime period of 2010.

\section{Methodology}

\subsection{ANN Technique}

The Artificial Neural Network package in MATLAB was used to develop a neural network model. The purpose of the model is to establish a correlation between the hourly-recorded building indoor air temperatures with the input parameters previously described. The Time Series Neural Network (TSNN) was utilized in this study to better encompass the dynamic nature of hourly temperature fluctuations within urban dwellings subjected to the UHI effects. The TSNN achieves such by incorporating past target data as additional input parameters while predicting the future target data. Therefore, when predicting the future hourly temperature within a dwelling, the TSNN incorporates past hourly temperatures in addition to the input parameters.

In order to establish a correlation between a set of input parameters and target data, the ANN divides the target data into three sets. The first set, designated as the training set, represents $70 \%$ of the target data that is chosen randomly by the network. The training set is used to establish the initial correlation between the input and target data by setting weights to each hidden layer. The validation process then follows, utilizing the validation set which is comprised of $25 \%$ of the target data that is randomly selected by the network. During the validation process, the network uses the hidden layer weights established during the training process to make predictions based on the input parameters that correlate with the validation set. The accuracy of the network is then evaluated by determining the mean squared error (MSE), comparing the predictions with the validation set of target data. This process of training and validating, defined as an Epoch, is repeated with the same training and validation sets until the accuracy of the network fails to improve for six successive iterations. The final process, defined as the testing process, utilizes the remaining $5 \%$ of the target data to evaluate the final performance of the network. During the testing process, the network uses the most accurate of the six Epochs that failed to improve during the validation process to make predictions for the entire set of data. The performance of the network is then evaluated by comparing the predictions with the entire set of target data and determining the MSE. It is important to note that only $5 \%$ of these predictions are the testing set, and therefore completely new data to the network.

\subsection{Radius of Influence}

As described by Mirzaei et Al. (2012), the heterogeneous surrounding environment significantly influences a building indoor thermal condition. Therefore, in developing a correlation between the factors that are known to facilitate the UHI and the resulting indoor conditions, it is necessary to investigate the influence of the urban environment surrounding the building of interest. However, the size of the surrounding environment that most significantly influences the indoor condition of a building has yet to be established. Investigating an area that is too small would result in an inaccurate and inconsistent correlation, as significant influential parameters may not be considered. However, investigating an area that is too large incorporates redundant information, and leads to an inaccurate representation of the surrounding influential environment.

If the urban environment surrounding a building is investigated as a circular area with the building in the center, it is logical to expect an optimal radius in which the resulting surrounding area produces the most accurate correlation without incorporating redundant information. This radius will be defined as the effective radius, indicating that the environment beyond its limit has 
negligible influence on the indoor condition of the building. This study investigates the effective radius size for multiple buildings by analyzing the area around each building from $20 \mathrm{~m}$ to $500 \mathrm{~m}$ in increments of $20 \mathrm{~m}$. A separate ANN model is developed for each radius, allowing the model performance to be presented as a function of the radius of the surrounding influential environment.

\section{Data collection and analysis}

\subsection{Data Measurement Campaign}

The data utilized for this study was acquired through a measurement campaign previously conducted by Park et al. (2010) in Montreal from May $1^{\text {st }}$ to September $8^{\text {th }}, 2010$. During which, the hourly indoor air temperature and relative humidity were recorded within 55 buildings throughout the Island of Montreal, each without mechanical ventilation systems. In addition, the physical characteristics of the buildings were recorded and used to evaluate additional input parameters that are defined below. The dwellings that were selected had no air conditioning equipment. The sensors were installed at a height of $1.5 \mathrm{~m}$ from the finished floor and away from windows to prevent solar radiation from altering the temperature readings. The air flow rate near the windows was also measured.

\subsection{Influential Parameters on Indoor Temperature}

In order to integrate the influence of the surrounding environment into the ANN, parameters that define the environment's influence are used as inputs to train the model. These parameters can be categorized into two major groups. First, land modification related parameters, which in fact represent the heat gained from sun and heat transferred by wind (i.e. solar heat gain, land-use, wind speed, street canyon aspect ratio, elevation of the measured temperature and E-ratio). Second, the thermal mass associated with pavement and the inhabitants who are living in the modified land.

\subsubsection{Land Modification Parameters}

Alteration of the natural land with the artificial materials increases the total solar heat gain, which is calculated for each building as a function of time of the day, and land-use ratio of the surrounding neighborhood.

Solar Heat Gain: The effects of solar radiation on the indoor temperature of a building can be a very tedious and complex process (Hutcheon et. al, 1995). However, many models are available to produce an estimate of the heat gain through solar radiation. In this study, both direct normal radiation and diffuse radiation were used in order to predict the radiation heat gain. The direct normal radiation was obtained using the weather data collected at the Pierre-Elliot Trudeau International Airport of Montreal. The diffuse radiation was calculated using the following equation (ASHRAE, 2005):

$I_{d}=I_{D N}\left[C F_{S S}+0.5 \rho_{g}(C+\sin \beta)\right]$

where $I_{d}$ is the total diffuse radiation $\left(\mathrm{W} / \mathrm{m}^{2}\right)$ and $I_{D N}$ represents the direct solar radiation $\left(\mathrm{W} / \mathrm{m}^{2}\right)$. The clearness index, $C$, is set to 0.134 for the month of June, 0.136 for the month of July, 0.122 for the month of August and 0.092 for the month of September. Only diffuse radiation on vertical surfaces is taken into consideration and therefore the view factor between the wall surfaces and the sky, $F_{S S}$, is equal to 0.5 . The ground reflectance was calculated by taking the reflectance of the materials of the six land uses and using the land use ratios as weights to obtain a single ground reflectance representative of the investigated area. Table 1 shows the six LULC categories 
considered in this study as well as their respective solar reflectance. The reflectance of water was assumed to be 0.1 because of the turbulence of the St-Laurence River surface.

Table 1. Solar reflectance of ground cover materials

\begin{tabular}{|c|c|}
\hline Ground Cover & Reflectance $\left.\boldsymbol{\rho}_{\boldsymbol{g}}\right)$ \\
\hline Grass & 0.25 \\
\hline Water & 0.1 \\
\hline Asphalt & 0.12 \\
\hline Concrete and Pavement & 0.5 \\
\hline Roof & 0.08 \\
\hline Vegetation & 0.16 \\
\hline
\end{tabular}

The solar altitude was obtained using the following equation (ASHRAE, 2005):

$\beta=\sin ^{-1}(\cos L \cos \delta \cos H+\sin L \sin \delta)$

The latitude of Montreal was taken as $45^{\circ}$ and the solar declination angle, $\delta$, for the months of June, July, August and September were taken as $23.45^{\circ}, 20.6^{\circ}, 12.3^{\circ}$ and $0^{\circ}$ respectively. The hour angle, $\mathrm{H}$, which gives the rotation of the earth from the apparent solar time to noon is calculated based on the equation of time (being -1.4 min for June, -6.2 min for July, -2.4 min for August and $+7.5 \mathrm{~min}$ for September), the local standard time, the local longitude $\left(73^{\circ}\right.$ for Montreal) and the local standard meridian $\left(75^{\circ}\right.$ for eastern) (Hutcheon et. al, 1995). The heat gain due to solar radiation is determined by taking into consideration all surfaces of the building. The following equation describes the heat gain through various surfaces of the building:

Heat Gain $=I_{d} \times A_{\text {window }} \times \tau+I_{d} \times A_{\text {vertical walls }} \times\left(1-\right.$ Albedo $\left._{\text {walls }}\right)+I_{D N} \times$ $A_{\text {roof }}\left(1-\right.$ Albedo $\left._{\text {roof }}\right)$

Only diffuse radiation is assumed to go through the windows with total area $A_{\text {window }}\left(\mathrm{m}^{2}\right)$ and transmittance $\tau$. Vertical walls are assumed to receive only diffuse radiation, incident on the area $A_{\text {vertical walls }}\left(\mathrm{m}^{2}\right)$ with a solar absorption of $1-$ Albedo $_{\text {walls }}$. The roof is assumed to receive a direct radiation on the area $A_{\text {roof }}\left(\mathrm{m}^{2}\right)$ with an absorption rate of $1-$ Albedo $_{\text {roof }}$.

Land-use Ratio: Previous studies have shown that the amount of vegetation surrounding a building affects the building's indoor temperature considerably. In their research, Mirzaei et al. (2012) analyzed the vegetation ratio as a percentage of land cover over an area of $10,000 \mathrm{~m}^{2}$ and included the presence of trees and bushes. Vegetation increases the air water content in close proximity to the plants and since water has a high specific heat, this has a tendency to decrease the air temperature. The proximity to a body of water has also been shown to have an effect on the phenomenon of urban heat island (Oke et al., 1971). Wind blowing over a body of water is substantially cooled since water has a high specific heat and is usually present in high quantities such as in rivers and lakes. In the case of the city of Montreal, this can become an important parameter, as the city is an island surrounded by the St-Laurence River. 
The method chosen to study the land use ratios of the neighborhoods of the selected buildings is to use satellite imagery. Fig. 1 shows the satellite image of the neighborhood around Chartrand Street in Northern Montreal.
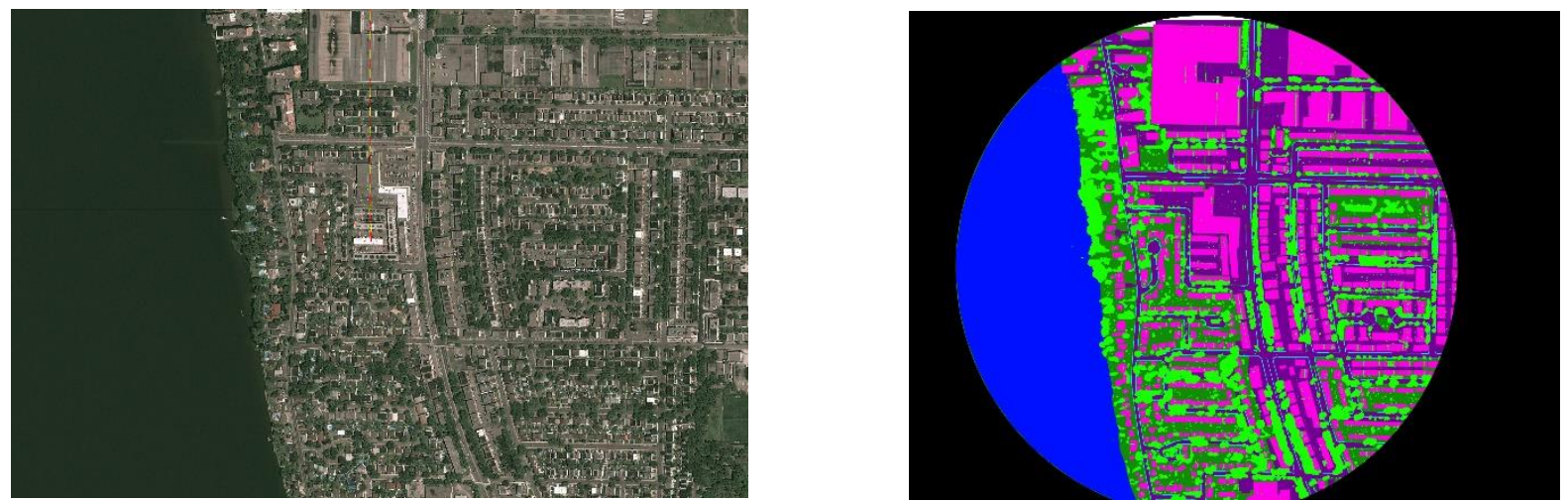

Fig.1. (Left) Satellite image of Chartrand street Montreal using Google Earth - (Right) processed satellite image of Chartrand street Montreal

The Image Processing Package available for MATLAB was chosen to analyze the satellite images. The land use ratios were thus entered in the artificial neural network in the form of a percentage of the total area being analyzed. In order to facilitate the investigation of the effective radius, unique sets of land use ratios were determined for each radius being investigated.

Wind speed: Urban roughness alters the convective heat transfer compared to that of rural areas. The wind flowing over and around a building considerably changes the cooling and heating loads of a building due to the convective heat transfer between the building envelope and the prevailing wind as well as the air infiltration/exfiltration. Wind speeds in the metropolitan area of Montreal are monitored at the Pierre-Elliot Trudeau International Airport. The wind profile deformation created by the surface roughness of neighborhoods with buildings, trees and other protruding elements is taken into consideration by the power law which is demonstrated by the following equation (Aynsley et al., 1977).

$\frac{\mathrm{v}_{\mathrm{z}}}{\mathrm{v}_{\mathrm{g}}}=\left[\frac{\mathrm{z}}{\mathrm{z}_{\mathrm{g}}}\right]^{\alpha}$

where $V_{Z}$ is the mean wind speed at specific height $(\mathrm{m} / \mathrm{s}), V_{g}$ is the mean wind speed at gradient height $(\mathrm{m} / \mathrm{s}), \mathrm{Z}$ is the specific height $(\mathrm{m}), \mathrm{Z}_{\mathrm{g}}$ is the gradient height $(\mathrm{m})$, and $\alpha$ is the mean speed coefficient.

Street canyon aspect ratio and room elevation: The wind profile monitored in the rural area is crossing various urban neighborhoods and thus is deformed in accordance with the local characteristic of that particular region. This implies that different rates of convection are expected with a variation of wind profile in the different locations of the city as well as with elevations of buildings. The street canyon aspect ratio is defined as the ratio of the building's height to the width of street. Room elevation represents the floor that the dwelling under study was located on as a fraction of the total number of floors within the building.

E-ratio: Another parameter, E-ratio, is also defined to present the convective impact of the building's surfaces as the fraction of dwelling envelope that is exposed to the exterior environment. The dwelling envelope is defined as the walls and the ceiling while excluding the floor. This 
parameter was included to represent the degree to which the dwelling exchanges heat directly with the outdoor environment:

$$
\mathrm{E}-\text { ratio }=\frac{\mathrm{EEA}}{\mathrm{EA}}
$$

where EEA is the exposed envelope area $\left(\mathrm{m}^{2}\right)$ and EA is the whole envelope area $\left(\mathrm{m}^{2}\right)$. A dwelling with an E-ratio of 0 is one where the entire envelope is adjacent to other rooms in a building and a dwelling with an E-ratio of 1 is one where all of the walls are exposed to the outdoors.

\subsubsection{Thermal Mass Parameters}

Internal heat gain due to occupancy: For each dwelling under study, the internal heat generation is estimated for the entire building. The three parameters considered in determining the level of heat generation are the metabolic heat generation due to human occupancy, lighting, and appliances.

Heat generated from the building occupants was estimated based on the number of occupants residing in the building, the age of occupants, and the type of occupant activity. The number of hours per day that each age group dedicates to each activity is firstly assumed. Age distributions, based on demographic information, are then used to approximate the number of occupants of each age group inside a dwelling. The sensible gain due to lighting fixtures within each building is estimated based on floor area using lighting power density (LPD), which corresponds to heat gain from lighting per square meter based on space type (ASHRAE, 2013). The floor area of each building is estimated based on the recorded depth and width of each building, as well as the number of floors. Moreover, the heat gain due to appliance usage within each building is estimated based on the heat generated by commonly used appliances (Hydro-Quebec, 2014,Otter Tail Company, 2014), as well as the assumed hours of operation per day per two people.

Neighborhood Building Thermal Mass: The thermal mass of a neighborhood has also been shown to have an effect on the magnitude of the urban heat island (Kolokotroni et al., 2009). By nightfall, as the temperature of the air decreases, the stored energy is dissipated to the air. The urban heat island effect is most observable by nightfall where the temperature difference between the island of Montreal and its neighboring rural areas can reach a maximum of $10^{\circ} \mathrm{C}$ (Oke et al., 1971). The building thermal mass was determined as the product of the average neighborhood building height and the building land cover percentage obtained through the processing of satellite images. The building thermal mass parameter was inputted in the network in the form of building volume. This implies that the thermal mass density is assumed to be similar for all buildings within a neighborhood.

Pavement Thermal Mass: The thermal mass of pavement and asphalt was determined as the product of the average paving thickness and the land cover percentage obtained through the processing of satellite images. An average thickness of $0.3 \mathrm{~m}$ was assumed for both asphalt and pavement. It was also assumed that the asphalt and the concrete used to pave the roads and sidewalks have a similar thermal storage capacity. The sum of the volumes of asphalt and pavement was therefore inputted in the network.

\subsection{Normalization of Data}

The network input data was normalized to prevent dominance of one parameter over other parameters, preventing faulty training of the network. The method chosen for the normalization of 
the data is to transform all data entries into numbers ranging from 0 to 1 using the following equation:

$$
\operatorname{Normalized}\left(e_{i}\right)=\frac{e_{i}-E_{\min }}{E_{\max }-E_{\min }}
$$

where $e_{i}$ is the data entry, and $E_{\min }$ and $E_{\max }$ are respectively the minimum and maximum values of data set. There is a maximum and minimum value determined for every parameter included in the training of the model. For each parameter, a script passes through every value of the dataset. The highest and lowest values are selected and used to normalize the dataset. The normalized entry to the ANN represents the actual value by a fraction indicating how close or far it is with respect to the minimum or maximum values. The same ANN model was run with and without normalization of data. An about 5\%improvement in the average MSE was obtained with normalizing the dataset.

\section{ANN Model Performance}

\subsection{Parametric Sensitivity Test}

A parametric sensitivity study was conducted in which various sets of input parameters were used to develop multiple ANNs, each defined as a simulation package. This was to determine the influence of urban structural elements on air temperatures in the vicinity of the buildings and thereafter on the indoor air temperature of the buildings. A parameter with a stronger influence over the indoor air temperature would be one where the ANN package can develop a model with the lowest MSE, indicating that a stronger correlation can be established. The parametric sensitivity study was divided into 3 simulation packages. Table 2 demonstrates simulation packages 1 through 3. Package 1 simulation represents the core parameters that have already been evaluated as critical in developing an accurate predictive ANN model (Mirzaei et al., 2012). Each subsequent package of simulation incorporates additional input parameters. Simulation packages 2 and 3 include the surrounding environment, and were therefore each simulated on 25 independent occasions, each with a unique prescribed radius, ranging from $20 \mathrm{~m}$ to $500 \mathrm{~m}$ in increments of $20 \mathrm{~m}$. The performance of each package of simulation was compared with that of the preceding package, assessing the impact that the additional input parameters had on the model's accuracy and precision.

Table 2. Parameters within each simulation package

\begin{tabular}{|c|c|c|}
\hline \multicolumn{3}{|c|}{ Package 3} \\
\hline Package & & \\
\hline Package 1 & & \\
\hline $\begin{array}{ll}\text { 1. } & \text { Winds } \\
\text { 2. } & \text { Occupancy } \\
\text { 3. } & \text { Solar Radiation } \\
\text { 4. } & \text { Dry-bulb temperature at airport } \\
\text { 5. Relative humidity at airport } \\
\text { 6. Street aspect ratio } \\
\text { 7. } \\
\text { 8. } \\
\text { 9. } & \text { E-raor our of the day }\end{array}$ & $\begin{array}{cl}\text { 10. Land-use ratios: } \\
\checkmark & \text { Grass } \\
\checkmark & \text { Trees } \\
\checkmark & \text { Water } \\
\checkmark & \text { Rooftops } \\
\checkmark & \text { Asphalt } \\
\checkmark & \text { Pavement }\end{array}$ &  \\
\hline
\end{tabular}




\subsection{Network Testing}

The ANN is used to establish a correlation between the hourly temperatures within buildings subjected to the UHI effects and the influential parameters. The ability for the ANN to predict the indoor temperature of buildings subjected to the UHI effects is representative of the influence that the input parameters have on the indoor temperature of building of interest. The parameters were chosen to be hourly instead of daily because as UHI effects are dynamic throughout a single day, and these effects were to be incorporated within the model. Therefore, the performance of the ANN is the basis in evaluating the degree to which certain parameters influence the interior environment of buildings, resulting from the UHI phenomenon.

In order to maintain consistent and adequate evaluation of the ANN performance, specific segments of the data were not included in process of developing the ANN as they were reserved for the final evaluation of the network. These excluded data sets contain the measured data for the time period of September $1^{\text {st }}$ to $8^{\text {th }}, 2010$ and the entire data set for Building \#37, located in Verdun (see Fig. 2). The time period of September 1st to 8th, 2010 was excluded from the network development process so that the network could be made to predict the hourly indoor temperature during that time period never yet seen by the network. This process therefore evaluates the networks ability to predict future indoor temperatures within buildings that were included in the development process. Similarly, excluding the data set for Building \#37 tests the network's ability to make predictions for buildings was not utilized in the development process. Building \#37 was selected as it exists in a highly populated residential neighborhood with a high risk of mortality and morbidity related to the UHI. 


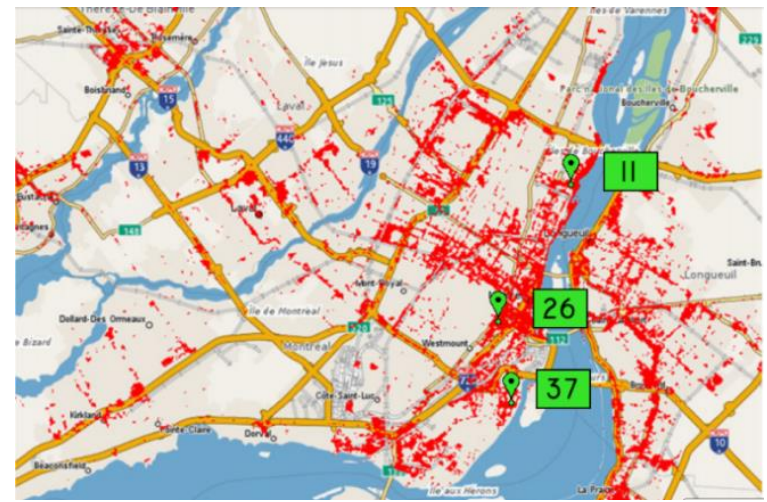

(a)

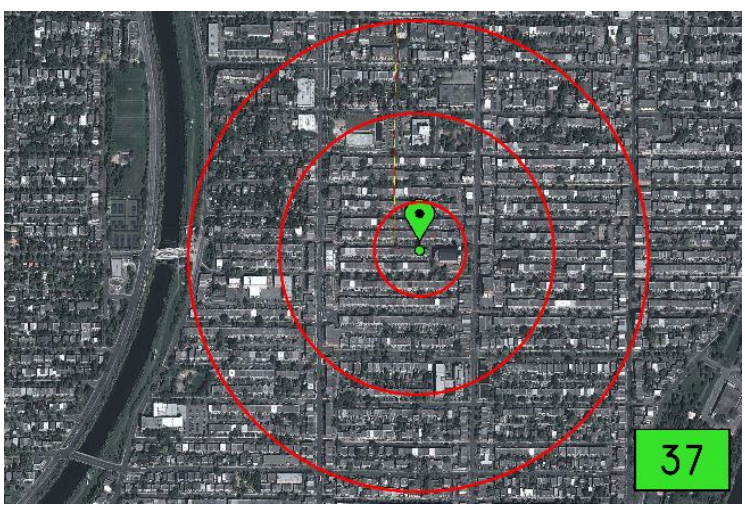

(c)

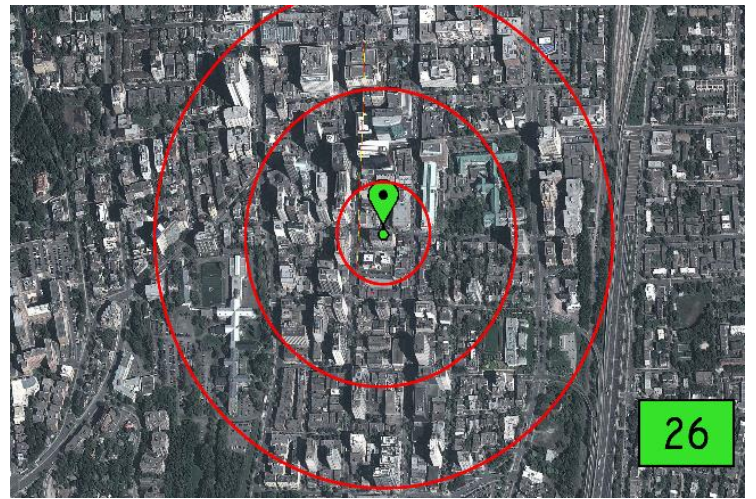

(b)

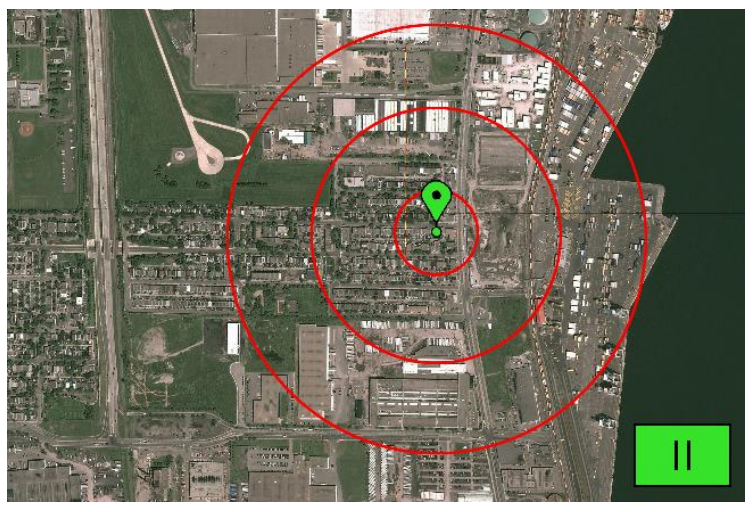

(d)

Fig. 2. (a) Montreal's significant UHI areas as well as the target buildings' locations (b) Downtown Neighborhood Building (\#26) (c) Residential Neighborhood Building (\#37) (d) Industrial Neighborhood Building (\#11)

In order to maintain a consistent and controlled evaluation of the network performance, specific buildings were selected to be the basis of the evaluation process. Buildings that demonstrate unique attributes were selected to evaluate the networks ability to predict indoor temperatures for a variety of dwelling types in a variety of environments. As illustrated in Fig. 2, building \#26 (Downtown Building) was chosen, as it is located in downtown Montreal, where the majority of the surrounding environment is high-rise built up, with very little vegetation. In addition, building \#37 (Residential Neighborhood Building) was chosen due to its relatively consistent LULC, encompassing significant amounts of both vegetation and low-rise built-up environment. Finally, building \#11 (Industrial Neighborhood Building) was chosen due to the significant variations in the LULC of the surrounding environment resulting from the building's close proximity to industrial areas. Radii of $100 \mathrm{~m}, 300 \mathrm{~m}$, and $500 \mathrm{~m}$ can be seen in Fig. 2. Table 3 presents the parameters inputted within the ANN model for each of the studied buildings at the optimal radius of influence.

Table 3. Model parameters at optimal radius for the studied buildings

\begin{tabular}{|l|c|c|c|}
\hline Parameter & $\begin{array}{c}\text { Downtown } \\
\text { Neighbourhood } \\
\text { Building }\end{array}$ & $\begin{array}{c}\text { Residential } \\
\text { Neighborhood } \\
\text { Building }\end{array}$ & $\begin{array}{c}\text { Industrial } \\
\text { Neighborhood } \\
\text { Building }\end{array}$ \\
\hline Optimal Radius (m) & 340 & 340 & 360 \\
\hline
\end{tabular}




\begin{tabular}{|l|c|c|c|}
\hline LULC Ratio - Grass (\%) & 0.036 & 0.209 & 0.222 \\
\hline LULC Ratio - Trees (\%) & 0.114 & 0.106 & 0.059 \\
\hline LULC Ratio - Water (\%) & 0.000 & 0.000 & 0.000 \\
\hline LULC Ratio - Pavement (\%) & 0.092 & 0.042 & 0.021 \\
\hline LULC Ratio - Asphalt (\%) & 0.384 & 0.286 & 0.458 \\
\hline LULC Ratio - Rooftops (\%) & 0.375 & 0.358 & 0.240 \\
\hline EEA & 0.110 & 0.620 & 0.830 \\
\hline Aspect Ratio & 1.465 & 0.388 & 0.220 \\
\hline Room Elevation Ratio & 1.000 & 0.388 & 1.000 \\
\hline Building volume $\left(\mathrm{m}^{3}\right)$ & $5,848,300$ & 910,380 & 683,900 \\
\hline Pavement volume $\left(\mathrm{m}^{3}\right)$ & 51,814 & 35,688 & 58,497 \\
\hline Population Density $\left(\right.$ habitants $\left./ \mathrm{km}^{2}\right)$ & 4,414 & 6,829 & 5,573 \\
\hline
\end{tabular}

\subsection{Network Prediction Refining and Evaluation}

The evaluation of the model was done using the mean square error (MSE) between the predicted temperatures and the actual temperatures:

$M S E=\frac{\sum\left(X_{t}-F_{t}\right)^{2}}{m}$

where MSE is the mean squared error, $\mathrm{X}_{\mathrm{t}}$ is the actual temperature at time $\mathrm{t}, \mathrm{F}_{\mathrm{t}}$ is the predicted temperature at time $t$, and $m$ is the size of data set.

Developing multiple networks with the same data sets yield different MSEs and therefore different levels of network performance. This is due to the fact that the random nature of the training process gives multiple networks different levels of experience with the different types of buildings within the total data set. In order to adequately evaluate the performance of a network by alleviating the effects of improper network development, the developmental process is repeated for 10 independent trials. The average MSE for the 10 trials is then used to evaluate the network's accuracy, while the standard deviation is used to evaluate the network's precision.

Discrepancies resulting from improper network development were further alleviated as the MSE values within each trial set were analyzed and refined, removing poorly performing networks. The data refining process was carried out using Grubb's method (Grubb, 1969) involving the computation of a test criterion, $T_{n}$, for every entry in the set and comparing it to a critical criterion to determine if it is an outlier. A computed value higher than the critical criterion is classified as an outlier. The test criterion is determined with the following equation:

$T_{n}=\frac{x_{n}-\bar{x}}{s}$

where $\bar{x}$ is the arithmetic average and $s$ is the standard deviation of the 10 trial data set. Table 4 demonstrates, $T_{n}$, for 10 trails.

Table 4. Table of critical values of $\mathrm{T}$ (one-sided test)

\begin{tabular}{|c|c|}
\hline $\begin{array}{c}\text { Number of } \\
\text { Observations "n" }\end{array}$ & $\begin{array}{c}\text { Critical Values of T } \\
\text { (5\% Significance Level) }\end{array}$ \\
\hline 3 & 1.15 \\
\hline 4 & 1.46 \\
\hline
\end{tabular}




\begin{tabular}{|c|c|}
\hline 5 & 1.67 \\
\hline 6 & 1.82 \\
\hline 7 & 1.94 \\
\hline 8 & 2.03 \\
\hline 9 & 2.11 \\
\hline 10 & 2.18 \\
\hline
\end{tabular}

Once the outliers for a radius and/or parameter are removed, the remaining MSE values are representative of the correlation between the input parameters and the target temperature values.

\section{Results and Discussion}

\subsection{Optimal Radius of Influence}

The average MSE for simulation Package 1, 2, and 3 are demonstrated in Fig. 3, 7 and 11 for the selected buildings. In each case, the performance is demonstrated as a function of radius, and therefore the size of area around the building under consideration. Note that the input parameters for Package 1 did not include LULC, and as a result, the performance of Package 1 is not a function of the radius of the surrounding area.

\subsubsection{Downtown Building (\#26)}

For the Downtown Neighborhood Building (see Fig. 2b), influential parameters resulting from surrounding LULC have considerable impact on the indoor temperature of the building. Furthermore, the most predominant aspect of the LULC that influences the indoor temperature is thermal mass, as indicated by the performance of Package 3, which is the only simulation to include such parameters. This observation can be explained by the fact that, in downtown Montreal, the majority of the environment surrounding the building is mainly composed of other buildings, asphalt and pavement, each with substantial mass. Therefore for the Downtown Neighborhood Building, the influence of LULC, relating to the amount of surrounding vegetation, water, and variance in diffuse solar radiation due to ground reflectance, has substantially less significance than the mass of the surrounding environment.

Although the average MSE of Package 3 fluctuates moderately due to the random nature of the ANN development process, it can be noted that from Fig. 3 there exists a moderate trend in the performance of the ANN with the increase of radius. The average MSE is consistently low for radii between 340 and $420 \mathrm{~m}$, meaning that the strongest correlation between input parameters, and indoor dry bulb temperature is achieved when the area around the building is considered to have a radius within this range. This indicates that for the case of the Downtown Neighborhood Building, the surrounding environment is the most critical in influencing the indoor temperature, and the effective radius of the surroundings environment is between 340 and $420 \mathrm{~m}$. The highest level of accuracy is achieved at $340 \mathrm{~m}$ with a minimal MSE of 0.65 . 




Fig. 3. Average indoor temperature MSE for the Downtown Neighborhood Building from September $1^{\text {st }}-8^{\text {th }}$

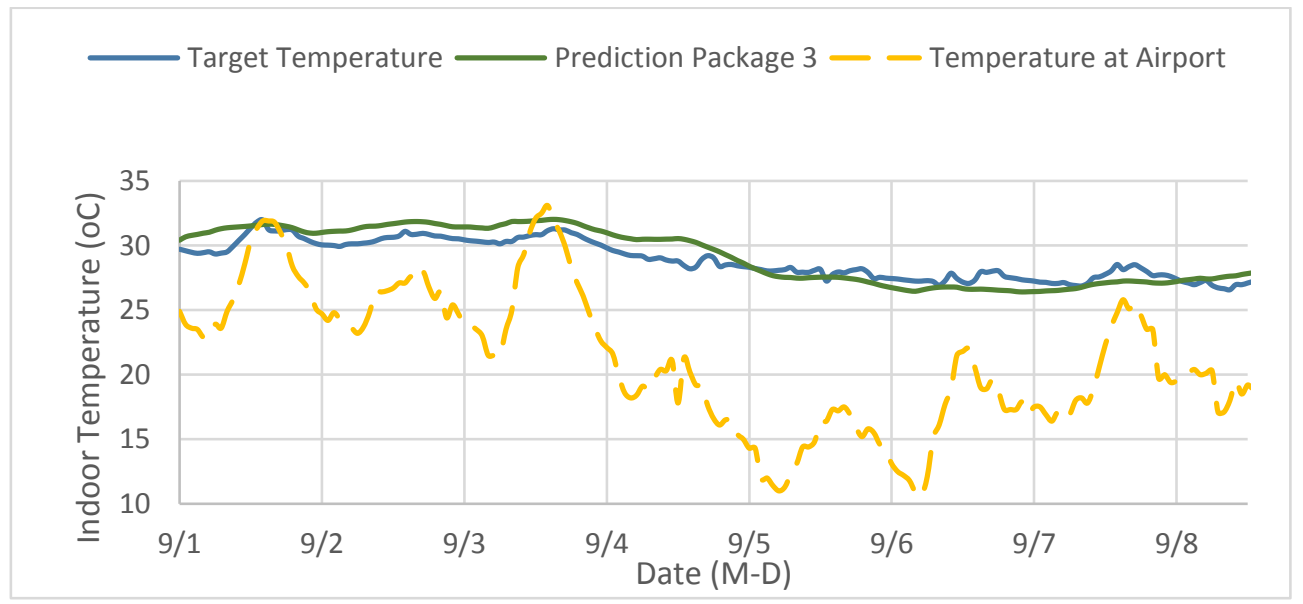

Fig. 4. Indoor temperature predictions for Downtown Neighborhood Building from September $1^{\text {st }}-8^{\text {th }}$ for radius $340 \mathrm{~m}$

Package 2

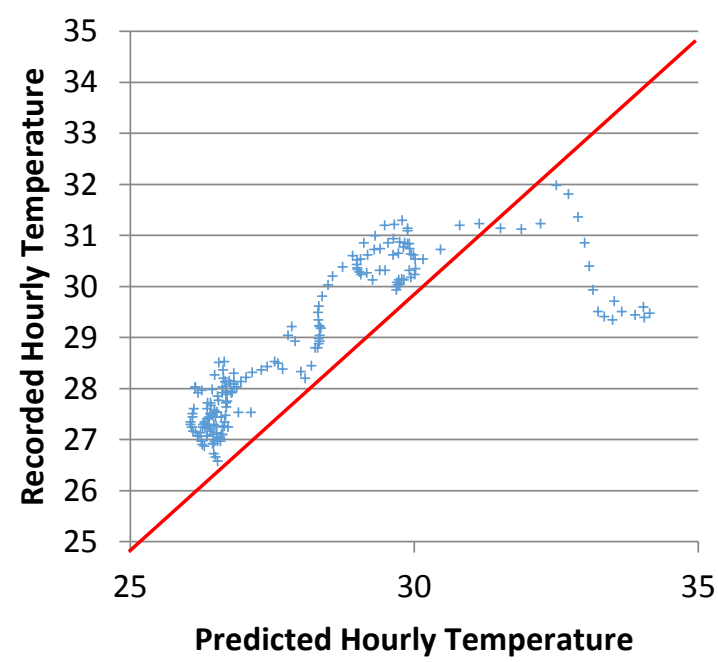

Package 3

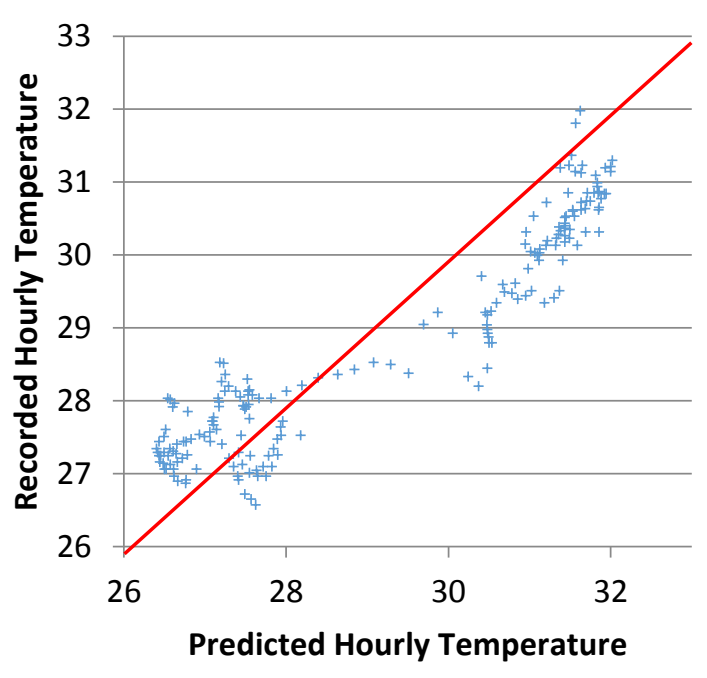


Fig. 5. Frequency distributions for the Downtown Neighborhood Building from September $1^{\text {st }}-8^{\text {th }}$

Fig. 4 shows the hourly temperature predictions of the Downtown Neighborhood Building from September $1^{\text {st }}$ to September $8^{\text {th }}$ from a network utilizing Package 3 and influential area with an effective radius of $340 \mathrm{~m}$. Fig. 5 shows the frequency distribution for packages 2 and 3 for the effective radius.

Note that the predictions made by the Package 3 model are a good representation of the temperature peaks. In the event of a heat wave, surface materials surrounding buildings store a considerable amount of heat, releasing it gradually thereafter. In that sense, it follows that Package 3 achieved a high level of performance, as demonstrated by Fig. 4 and 5, because it incorporates the presence of the considerable thermal mass within the surrounding environment.

\subsubsection{Residential Neighborhood Building (\#37)}

As explained earlier, the test of the Residential Neighborhood Building (see Fig. 2c) from September $1^{\text {st }}$ to $8^{\text {th }}$ evaluates the networks ability to predict indoor temperatures within a new building for a new time period. As it is demonstrated in Fig. 6, simulation Package 2 produces moderately more accurate and precise predictions than Package 1, while Package 3 produces considerably more accurate and precise predictions than Package 2. This trend is consistent with the results of the Downtown Building from September $1^{\text {st }}$ to September $8^{\text {th }}$. This indicates that the influential parameters resulting from the LULC of the surrounding environment have considerable influence over the indoor temperature.

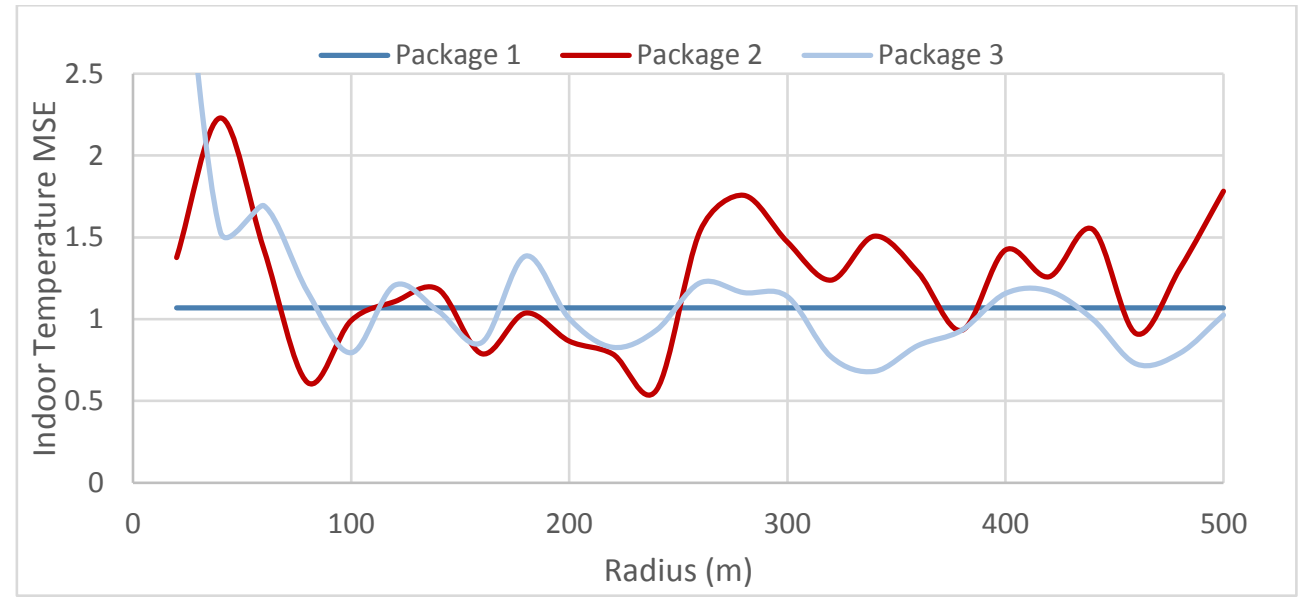

Fig. 6. Average indoor temperature MSE for the Residential Neighborhood Building from September $1^{\text {st }}-8^{\text {th }}$

Note that the addition of thermal mass has less influence in improving the accuracy and precision of the network than in the case of the Downtown Building. This observation can be explained by the fact that the environment surrounding the Residential Neighborhood Building has less mass (light weight low-rise residential) compared to those heavy concrete high-rise buildings located in downtown area. As a result, the thermal mass does not have as influential impact as other parameters resulting from surrounding LULC.

Fig. 6 also demonstrates that both the accuracy and precision of simulation Package 3 again follow a moderate trend with increasing radius from the building. The network achieves highest performance levels within the range of 320 and 360m, reaching a minimal MSE of 0.681 at 340m. This again indicates that the surrounding environment that is most critical in influencing the indoor 
temperature, and therefore the effective radius of the Residential Neighborhood Building, exists within a 320 and $360 \mathrm{~m}$.

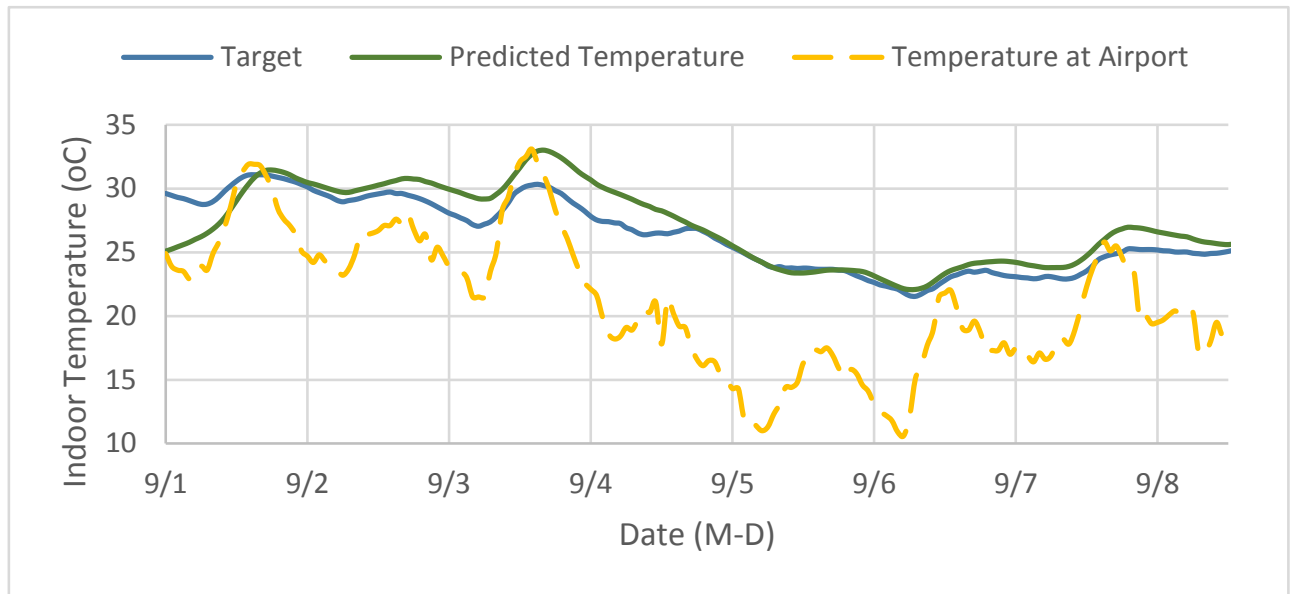

Fig. 7. Indoor temperature predictions for Residential Neighborhood Building from September $1^{\text {st }-8^{\text {th }}}$ for radius $340 \mathrm{~m}$

Package 2

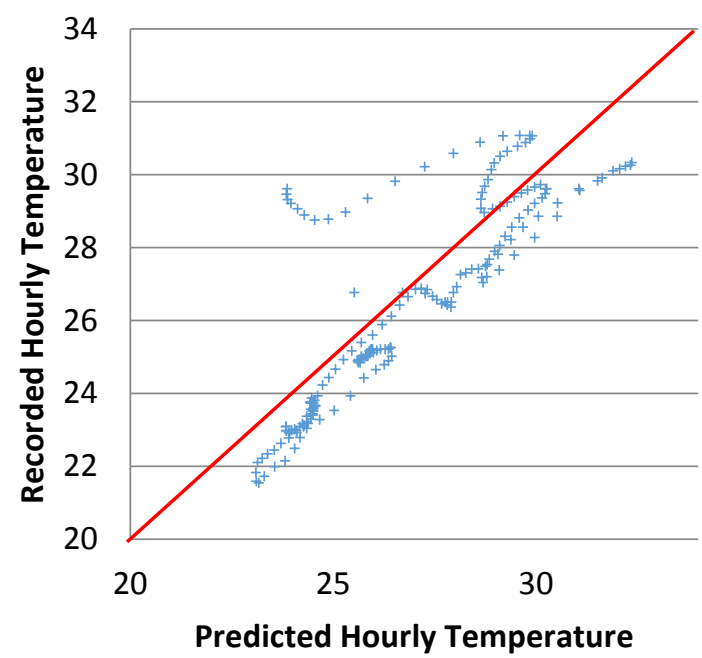

Pachage 3

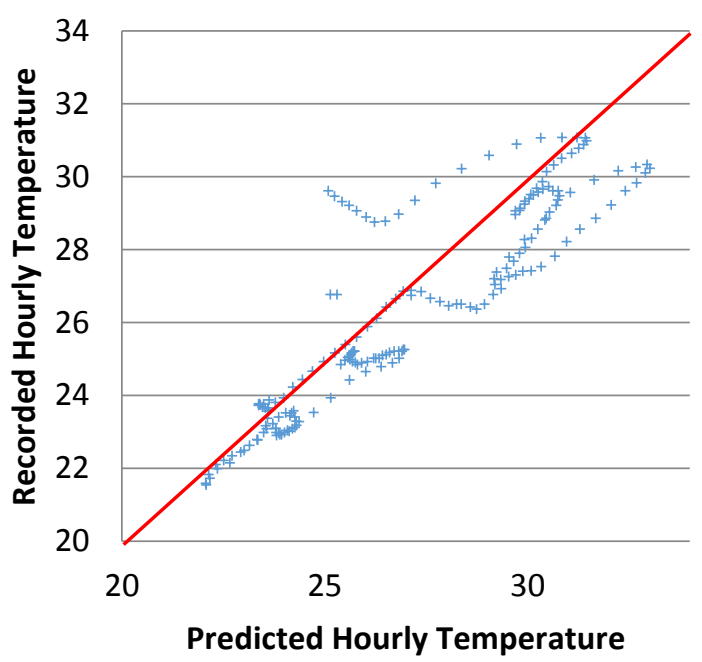

Fig. 8. Frequency distributions for the Residential Neighborhood Building from September $1^{\text {st }}$ $8^{\text {th }}$

Fig. 7 shows the temperature predictions for the Residential Neighborhood Building from September $1^{\text {st }}$ to September $8^{\text {th }}$ from a network utilizing Package 3 and influential area with a radius of $340 \mathrm{~m}$. Note the close proximity of the time lag between the airport temperature and the building's internal temperature, indicating that the network effectively incorporates the effects of the thermal storage capacity of the surrounding neighborhood. Fig. 8 shows the frequency distribution for packages 2 and 3 for the effective radius of $340 \mathrm{~m}$.

\subsubsection{Industrial Neighborhood Building (\#11)}

As it is shown in Fig. 9, the simulation Packages produce similar results as the Residential Neighborhood Building and the Downtown Building such that Package 2 has moderately better 
accuracy than Package 1 while Package 3 has considerably better accuracy than Package 2. The figure therefore once again indicates that LULC and thermal mass have significant influence on the indoor temperature of Building 11. It can once again be noted that Package 3 demonstrates a moderate trend with increasing radius such that the greatest accuracy and precision occurs within a range of 340 and $380 \mathrm{~m}$, reaching a minimal MSE of 2.03 at $360 \mathrm{~m}$.

Fig. 10 shows the temperature predictions for the Industrial Neighborhood Building from September $1^{\text {st }}$ to September $8^{\text {th }}$ from a network utilizing Package 3 and influential area with a radius of $360 \mathrm{~m}$. Again, the network predicts the time lag between the airport temperature and the building's internal temperature, indicating that the network effectively incorporates the effects of the thermal storage capacity of the surrounding neighborhood. Fig. 11 the frequency distribution for packages 2 and 3 for the effective radius.

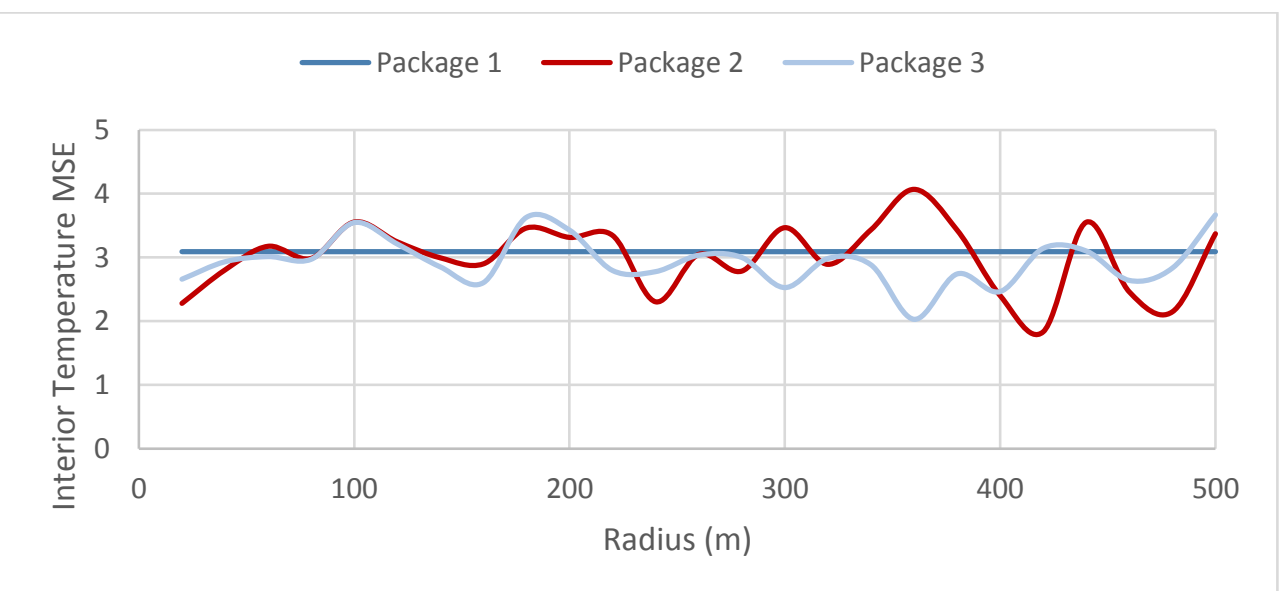

Fig. 9. Average indoor temperature MSE for Industrial Neighborhood Building from September $1^{\text {st }}-8^{\text {th }}$

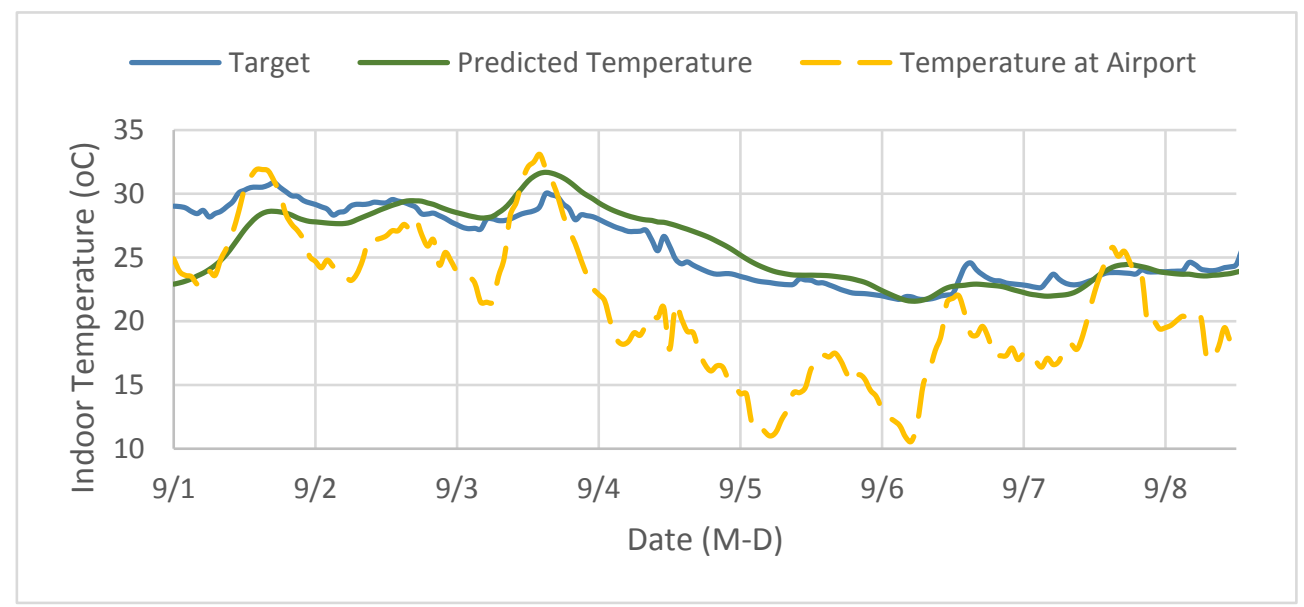

Fig. 10. Indoor temperature predictions for Industrial Neighborhood Building from September $1^{\text {st }}-8^{\text {th }}$ for Radius of $360 \mathrm{~m}$ 
Package 2



Package 3

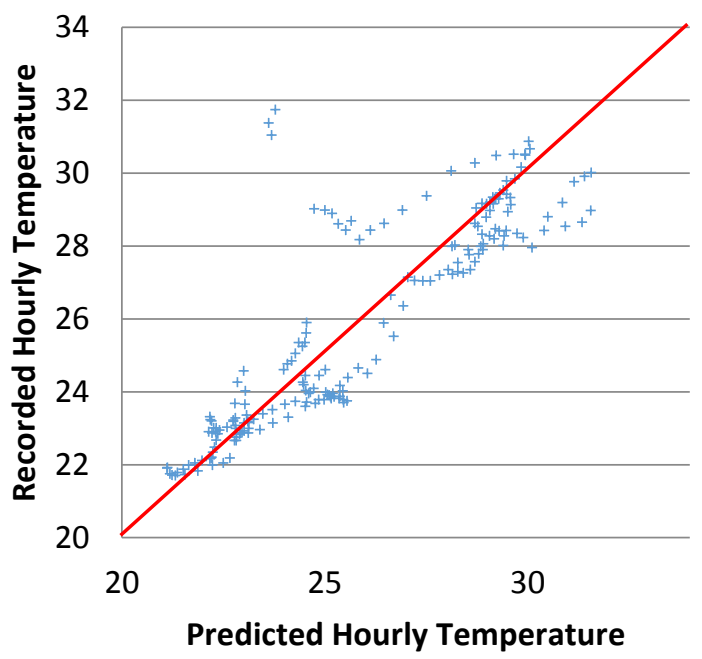

Fig. 11. Frequency distributions for the Industrial Neighborhood Building from September $1^{\text {st }}-8^{\text {th }}$

\subsection{Mitigating Strategies of UHI Effect}

As stated before, the goal of this study was to develop a predictive tool that is capable of modeling the behaviour of urban dwellings subjected to UHI effects. By establishing a correlation between the indoor environment of a building and the critical influential parameters of the surrounding environment, the tool is capable of both forecasting future hazards, as well as evaluating the effectiveness of potential neighborhood mitigation strategies. The tool's ability to perform the latter is tested by simulating the previous time periods with altered LULC ratios.

Potential mitigation strategies relating to an increase in neighborhood vegetation and a subsequent decrease in solar absorbing surfaces are evaluated on the Residential Neighborhood Building (\#37). The surrounding neighborhood has sufficient potential for the implementation of such mitigation strategies as it is divided into blocks, each having two rows of apartment buildings with an asphalt alley in between. In order to facilitate a feasible increase in neighborhood vegetation, it is assumed that the alleys would be completely replaced with green space and that some buildings would become equipped with green roofs.

The characteristics of the $360 \mathrm{~m}$ radial area surrounding the Residential Neighborhood Building are adjusted to model the implementation of the proposed increase in neighborhood vegetation. The LULC ratio of vegetation is increased by $1.0 \%$ by increasing the ratios of grass and trees by $0.3 \%$ and $0.7 \%$, respectively. Subsequently, surfaces with high solar absorption are decreased by $1.0 \%$ by decreasing the ratios of asphalt pavement and building rooftops by $0.8 \%$ and $0.2 \%$, respectively.

Based on the adjusted LULC ratios, the network is then used to predict the hourly indoor temperature of the Residential Neighborhood Building. Comparisons between the original predictions and the predictions based on the adjusted LULC ratios are used as the basis of evaluating the effectiveness of the proposed mitigation strategy. The process of increasing the vegetation ratio by $1 \%$, decreasing solar absorbing surfaces by $1 \%$, and then predicting the hourly indoor temperatures of the building is repeated until the vegetation ratio is increased by $19 \%$. Such 
was done to investigate the relationship between increasing levels of vegetation and decreasing indoor building temperatures. Fig. 15 demonstrates the average hourly temperature change as a function of the percentage of increase in neighborhood vegetation ratio for the time periods of June $6^{\text {th }}$ to September $8^{\text {th }}$.

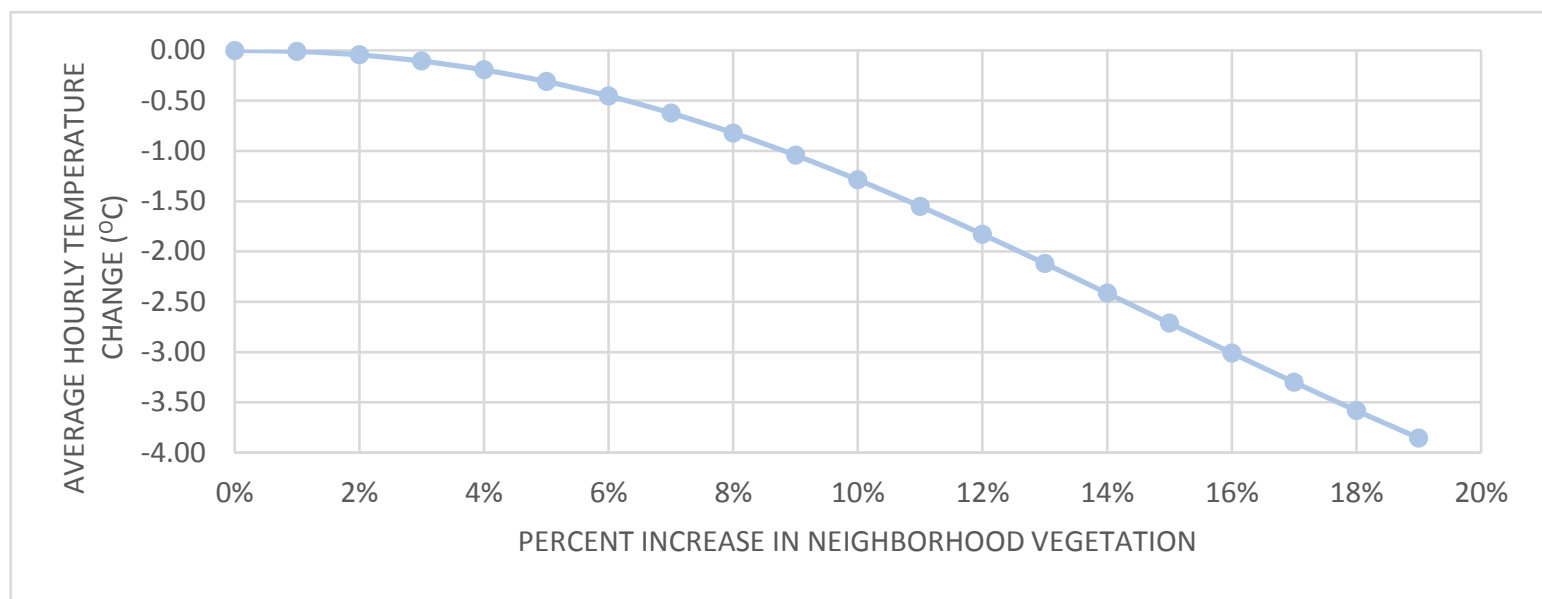

Fig. 15. Average temperature changes resulting from mitigation strategies for Residential Neighborhood Building for a $360 \mathrm{~m}$ radius

As it is demonstrated in Fig. 15, the average hourly temperature for the building over the period of June $6^{\text {th }}$ to September $8^{\text {th }}$ continually decreases with increasing neighborhood vegetation. The rate of temperature reduction is moderate for the first 5\% increase in vegetation, and then becomes more significant and with further increase in vegetation. This indicates that for the case of the Residential Neighbourhood, considerable increases in vegetation are required to produce significant improvements in the indoor environment of buildings within it. Fig. 16 demonstrates the neighborhood surrounding of the building if the vegetation ratio is increased by $15 \%$.

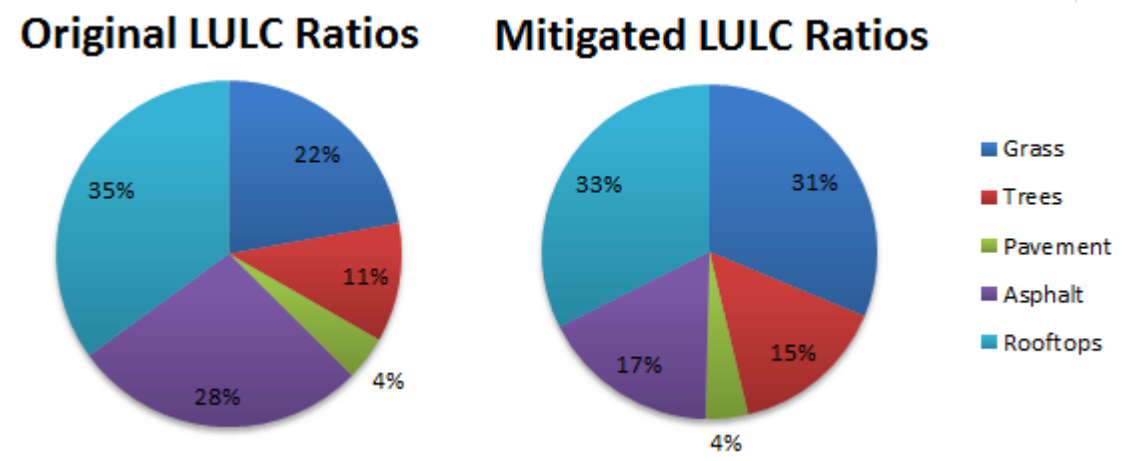

Fig. 16. Original and mitigated LULC ratios

As it is shown in Fig. 17, increasing the vegetation ratio of the Residential Neighborhood by $15 \%$ would significantly reduce the resulting hourly indoor temperatures. The average difference between the original LULC prediction and the mitigated LULC prediction suggests that a $2.8^{\circ} \mathrm{C}$ average reduction in building temperature can be achieved. In addition, it can be noted that the amount to which the indoor temperature is decreased is not constant for every hour, but rather, a greater reduction in temperature is achieved during times of high temperature peaks. Indeed, 
between September $1^{\text {st }}$ and September $4^{\text {th }}$ a maximum temperature reduction of $3.5^{\circ} \mathrm{C}$ was predicted by the network.

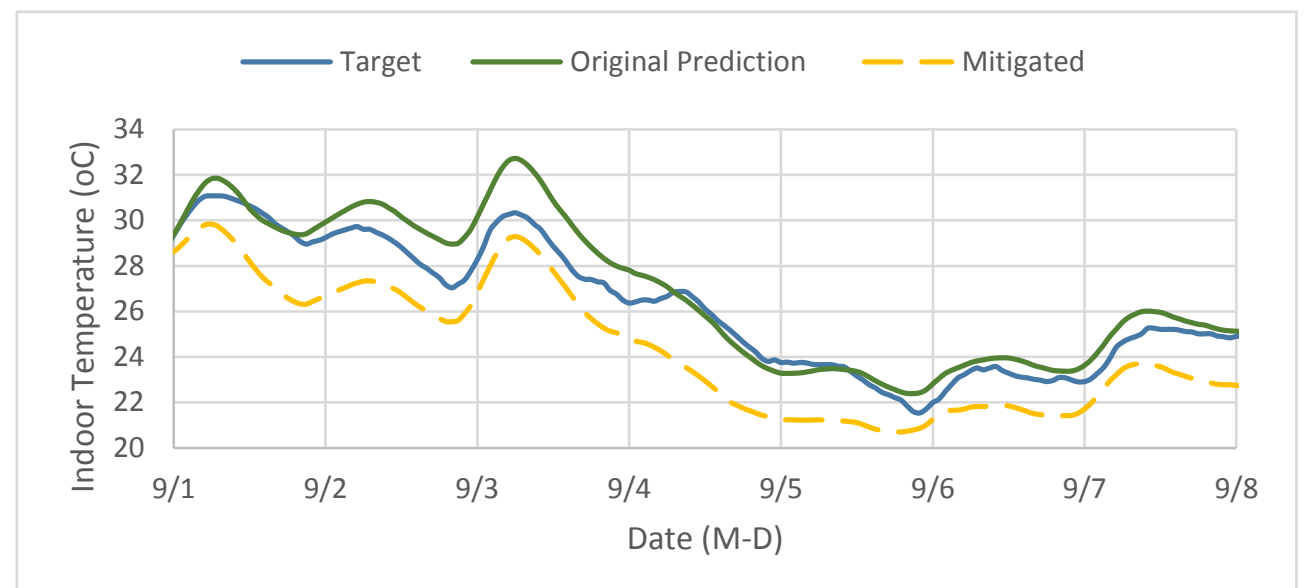

Fig. 17. Comparison between original indoor and mitigated indoor temperature prediction

The applicability of this tool to evaluate mitigation strategies is restricted to strategies involving the parameters used in the training of the model. As it is shown in Table 2, the developed ANN is trained based on exterior urban elements. Therefore, only mitigation strategies involving LULC ratios, thermal mass as well as the parameters included in simulation Package 1 can be evaluated by this approach. Therefore, parameters such as quantity of insulation, quantity of southfacing windows, area of windows, location of thermal mass within building and the geometry of the building that can have an influence on the indoor temperature of the building are not considered in the trained ANN. Future work is suggested to assess the effectiveness of these neglected parameters on a building's indoor temperature.

Despite the strength of ANN technique on establishing correlation between input and output dataset over conventional techniques such as regression, the major drawbacks of ANN is its high dependency on the training set. The output of the model gives reliable data as long as the input lies within the range of values in which it was trained. This drawback from the ANN approach became evident when attempting to predict indoor temperatures for the downtown Montreal building. The dataset used to train the model included 55 buildings, of which very few were downtown.

\section{Conclusion}

Neighborhood characteristics like thermal mass and LULC ratios were proven to have considerable influence on the interior temperature of a non-mechanically ventilated building. In this study, an ANN was developed in order to predict a building's interior temperature as a function of the surrounding environment for various buildings throughout Montreal. The weather conditions at the airport and building neighborhood characteristics that have already been proven to be influential by Mirzaei et al. (2010) were implemented in conjunction with building neighborhood thermal mass and LULC ratios. The thermal mass of the neighborhood included both buildings and pavement while the LULC ratios included grass, trees, water, concrete pavement, asphalt pavement, and building rooftops. The field measured data was used for the training and validation sets of the ANN. 
Thermal mass and LULC ratios were assessed as a function of radial distance from the buildings in order to establish the effective radius of influence. It was established that the effective radius at which neighborhood characteristics have negligible influence on the building indoor temperature lies in the range of $320 \mathrm{~m}$ to $380 \mathrm{~m}$. Moreover, the performance of the network for forecasting future indoor temperatures was evaluated utilizing hourly temperature data, which were not included in the network development/training process. Such was established as the network predicted the hourly indoor temperature of the Residential Neighborhood Building from September $1^{\text {st }}$ to $8^{\text {th }}$, producing a minimal MSE of 0.68 . The network was also used to evaluate the effectiveness of potential mitigation strategies through predicting the hourly indoor temperature of the Residential Neighborhood Building with an increase in surrounding vegetation and subsequent decrease in asphalt and bare rooftops. It was shown that, with an increase in vegetation of $15 \%$ in terms of total LULC, the interior temperature of the Residential Neighborhood Building can decrease by as much as $3.5^{\circ} \mathrm{C}$ in a heat wave and $2.8^{\circ} \mathrm{C}$ on average over a summer season.

\section{ACKNOWLEDGMENT}

The authors would like to express their gratitude to the Natural Sciences and Engineering Research Council of Canada (NSERC) for supporting this research project through undergraduate student research awards, and to Concordia University through Research-Chair award.

\section{References}

- American Society of Heating, Refrigerating and Air Conditionning Engineers (ASHRAE), ASHRAE handbook of fundamentals, 2005.

- American Society of Heating, Refrigerating and Air Conditioning Engineers (ASHRAE), ASHRAE Handbook of Fundamentals, 2013.

- Ashtiani A., Mirzaei P.A., Haghighat F., 2014. Indoor thermal condition in urban heat island: Comparison of the artificial neural network and regression methods prediction. Energy and Buildings 76 597-604.

- Basu R., and Samet J.M., 2002. Relation between Elevated Ambient Temperature and Mortality: A Review of the Epidemiologic Evidence. Epidemiologic Reviews, Vol. 24, No. 2

- Chen D., Wang X., Thatcher M., Barnett G., Kachenko A., Prince R., 2014. Urban vegetation for reducing heat related mortality. Environmental Pollution 192, 275-284.

- Coseo P., Larsen L., 2014. How factors of land use/land cover, building configuration, and adjacent heat sources and sinks explain Urban Heat Islands in Chicago. Landscape and Urban Planning 125, 117-129.

- Chun B., Guldmann J.M., 2014. Spatial statistical analysis and simulation of the urban heat island in high-density central cities. Landscape and Urban Planning 125, 76-88.

- Doyon B., Bélanger D., Gosselin P., 2008. The potential impact of climate change on annual and seasonal mortality for three cities in Québec, Canada. International Journal of Health Geographics, 7:23.

- Gabriel K.M.A., Endlicher W.R., 2011. Urban and rural mortality rates during heat waves in Berlin and Brandenburg, Germany. Environmental Pollution 159 (2011) 2044-2050.

- Grubb F.E., "Procedures For Detecting Outlying Observations in Samples," Technometrics, vol. 11, no. 1, pp. 1-21, 1969.

- Hutcheon, Neil B.; Handegord, Gustav O.P.;, Building Science for a Cold Climate, Institute for Research in Construction, 1995. 
- Hydro Quebec, "Consumption of Appliances," [Online]. Available: http://www.hydroquebec.com/energywise/calculation-tools/index.html. [Accessed 5 August 2014].

- Ivajnsic D., Kaligaric M., Ziberna I., 2014. Geographically weighted regression of the urban heat island of a small City. Applied Geography 53, 341-353.

- Kolokotroni M., Y. Zhang and R. Giridharan, "Heating and Cooling Degree Day Prediction Within the London Urban Heat Island Area," Building Services Engineering Research \& Technology, vol. 30, no. 3, pp. 183-202, 2009.

- Meehl, G.A., Tebaldi, C., 2004. More intense, more frequent, and longer lasting heat waves in the 21 st century. Science 305, 994-997.

- Mirzaei P.A., Haghighat F., 2010. Approaches to study urban heat island--abilities and limitations. Building and Environment, 45(10), 2192-2201.

- Mirzaei P.A., Haghighat F., Nakhaie, A., Yagouti A., Keusseyan R., Coman A., 2012. Indoor thermal condition in urban heat island-development of a predictive tool, Building and Environment, 57, 7-17.

- Otter Tail Power Company, "Appliance Energy Usage," [Online]. Available: http://www.otpco.com/SaveEnergyMoney/applianceEnergyUsage.asp. [Accessed 5 August 2014].

- Santamouris M., 2014. On the energy impact of urban heat island and global warming on buildings. Energy and Buildings 82, 100-113.

- Oke T. and East C., "The Urban Boundary Layer In Montreal," Boundary Layer Meteorology, pp. 411-437, 1971.

- Yuan-Fong Su Y.F., Foody G.M., Cheng K.S., 2012. Spatial non-stationarity in the relationships between land cover and surface temperature in an urban heat island and its impacts on thermally sensitive populations. Landscape and Urban Planning 107, 172- 180.

- Zheng B., Myint S.W., Fan C., 2014. Spatial configuration of anthropogenic land cover impacts on urban warming. Landscape and Urban Planning 130, 104-111.

- Park K.W., Akbari H., Haghighat F., Measuring, Modeling Indoor Thermal Conditions in Urban Heat Island Areas: The Case of Montreal Island, Montreal, 2010.

- Aynsley R.M., Melbourne W., and Vickery B.J., Architectural Aerodynamics, Applied Science Publishers Ltd., London, 1977. 